DRUG ALERT

\title{
Recommendations pertaining to the use of viral vaccines: Influenza 2013
}

\author{
Department of Health \\ Corresponding author: B D Schoub (barrys@nicd.ac.za)
}

Here we provide recommendations for the use of viral vaccines in anticipation of the 2013 Southern Hemisphere influenza season. For a review of the 2012 influenza season, please refer to the website of the National Institute for Communicable Diseases of the National Health Laboratory Service (http://www.nicd.ac.za).

S Afr Med J 2013;103(2):80. DOI:10.7196/SAMJ.6435

\section{Recommended vaccine formulation}

The following strains have been recommended by the World Health Organization (WHO) for the 2013 Southern Hemisphere influenza season:

- an A/California/7/2009 (H1N1)-like virus

- an A/Victoria/361/2011 (H3N2)-like virus

- a B/Wisconsin/1/2010-like virus.

Vaccines should contain $15 \mu \mathrm{g}$ of each haemagglutinin antigen in each $0.5 \mathrm{ml}$ dose.

\section{Indications}

- Persons (adults or children) who are at high risk for influenza and its complications because of underlying medical conditions and who are receiving regular medical care for conditions such as chronic pulmonary and cardiac diseases, chronic renal diseases, diabetes mellitus and similar metabolic disorders; individuals who are immuno-suppressed (including $\mathrm{HIV}$-infected persons with CD4 counts $>100$ cells $/ \mu \mathrm{l})$; and individuals who are morbidly obese (BMI $\geq 40 \mathrm{~kg} / \mathrm{m}^{2}$ ).

- Pregnant women - irrespective of the stage of pregnancy.

- Residents of old-age homes, chronic care and rehabilitation institutions.

- Children on long-term aspirin therapy.

- Medical and nursing staff responsible for the care of high-risk cases.

- Adults and children who are family contacts of high-risk cases.

- All persons aged $>65$ years.

- Any persons wishing to protect themselves from the risk of contracting influenza, especially in industrial settings, where large-scale absenteeism could cause significant economic losses.

\begin{tabular}{|c|c|c|c|}
\hline Age group & Weight (kg) & Oseltamivir dosage $^{\star}$ & Zanamivir dosage $^{*}$ \\
\hline Adults & & 75 mg twice a day & $\begin{array}{l}\text { Two } 5 \mathrm{mg} \text { inhalations } \\
\text { (10 mg total) twice a day }\end{array}$ \\
\hline $\begin{array}{l}\text { Premature neonates } \\
\text { ( }<38 \text { weeks) }\end{array}$ & & $1 \mathrm{mg} / \mathrm{kg}$ twice a day & \\
\hline Infants (0 - 12 months) & & $3 \mathrm{mg} / \mathrm{kg}$ twice a day & \\
\hline \multirow[t]{4}{*}{ Children } & $\leq 15$ & 30 mg twice a day & \multirow{4}{*}{$\begin{array}{l}\text { Two } 5 \mathrm{mg} \text { inhalations } \\
\text { ( } 10 \mathrm{mg} \text { total) twice a day } \\
\text { (only in children aged } 12 \\
\text { years or older) }\end{array}$} \\
\hline & $15-23$ & $45 \mathrm{mg}$ twice a day & \\
\hline & $24-40$ & $60 \mathrm{mg}$ twice a day & \\
\hline & $>40$ & 75 mg twice a day & \\
\hline
\end{tabular}

\section{Dosage}

- Adults: Whole or split-product or subunit vaccine, 1 dose intramuscularly (IM).

- Children (aged <12 years): Splitproduct or subunit vaccine, 1 dose IM.

- Children aged $<9$ years who have never been vaccinated should receive 2 doses 1 month apart.

- Children aged <3 years should receive half the adult dose on two occasions 1 month apart.

- Influenza vaccine is not recommended for infants aged $<6$ months.

\section{Contra-indications}

- Persons with a history of severe (anaphylactic) hypersensitivity to eggs or other components of the vaccine.

- Persons with acute febrile illnesses should preferably be immunised after symptoms have resolved.

\section{Timing}

Vaccines should be given sufficiently early to provide protection for the winter. A protective antibody response takes about 2 weeks to develop.

\section{Antiviral chemotherapy}

At present novel influenza A (H1N1) and $\mathrm{H} 3 \mathrm{~N} 2$ and B influenza viruses remain largely sensitive to oseltamivir (as well as zanamivir). Antiviral chemotherapy is most effective when administered as early as possible, $<2$ days after onset of illness. The dosages for treatment are provided in Table 1.

\section{Antiviral chemoprophylaxis}

Chemoprophylaxis for contacts of persons with influenza is not recommended. Recent WHO recommendations advise presumptive treatment using the treatment regimen described above for high-risk (severely immuno-compromised) individuals exposed to influenza instead of the previously recommended long-term lower-dose chemoprophylaxis regimen. These individuals need to be very carefully monitored during influenza season for early signs and should then be treated immediately on suspicion of infection.

For a more detailed description of antiviral management and prophylaxis of influenza, please refer to the Healthcare Workers Handbook on Influenza on the NICD website (http://www.nicd.ac.za). 